for the six parts of the triangle PZS. Please write direct to me at H.M. Nautical Almanac Office, Royal Greenwich Observatory, Herstmonceux Castle, Hailsham, Sussex.

The adopted notation for the five main parts (the parallactic angle is of lesser navigational importance) should also be capable of logical extension, firstly for co-latitude, polar distance and zenith distance, and secondly for the parts obtained by dividing the triangle into two right-angled (or right-sided) triangles; other auxiliary quantities may also be required. But this is subsidiary to the main problem, which should be decided on the basis of present usages rather than by means of a completely new system.

\title{
Bad Language
}

\author{
E. W. Anderson \\ (Smiths Aviation Division)
}

\section{The Requirement}

The prime object of any learned body is to communicate, either in writing or by word of mouth. Communication demands a common language and hence the Institute of Navigation must be vitally concerned with the language of navigation. Anyone who has read the remarkable navigation dictionary compiled by Alton B. Moody 1 will realize how much confusion exists.

It can be claimed that, on the bridge or on the flight deck, there is no problem. Each transport company, or at least each captain, presumably attaches precise meanings to the terms used in the individual craft. Were this all that navigation involves, terminology would not matter. But navigation today involves scientists, engineers, instructors and lawyers and information needs to be translated from one language into another. Information also needs to be interchanged between the various fields of navigation and these frequently overlap. For example, marine and air navigation overlap in naval aircraft and in hovercraft.

The requirement for a common terminology is particularly important to the man who has to produce navigational equipment and technical data for the operator of the craft. It was for such reasons that Smiths Aviation Division produced their Air Navigation Terminology 2 in 1961, a document which brought to light conflicts in the use of words even in the narrow field of civil air navigation.

\section{Attacking the Problem}

The navigator is an individualist who uses words as convenient for his work. Navigation is a science which covers a wide field of disciplines and each discipline has its own terminology. Small wonder that the resulting mixture of idiom and scientific jargon has led to a hotch-potch of navigation terms. Nevertheless, an examination of the way that sea and air navigators use words shows that, in general, there is an extraordinarily close agreement when the precise use of such 
words is necessary and that only when the sense is obvious do words tend to be used slackly. This slackness has led outsiders to believe that the terms themselves are ambiguous and has encouraged specialists to give general terms a specialized meaning and specialized terms a general meaning, thus adding still further to the general confusion.

It may be that the first step will be to re-state the true meaning of terms as generally recognized by navigators. These terms are often part of everyday English so that it will be important to ensure that they do not conflict with the normal usage outside navigation. By thus emphasizing what is good language, it may be possible to discourage bad language.

It may be objected that, even if a common language were to be agreed by Institutes, the individual navigator would continue to use words in the way to which he has become accustomed. However, we have suggested that his way is generally the right way. In any event, once terms had been established, they would be taught in navigation schools and would then gradually come into general use.

To illustrate the possibilities of agreement let us examine a few key terms. Three pairs of words have been chosen as follows:

(a) Course and Track.

(b) Drift and Crab.

(c) Height and Altitude.

Course and Track

The navigator, unlike certain specialists, distinguishes clearly between lines and directions. A direction is a reference which applies to a point and has neither length nor breadth. Thus a meridian is the direction of the Sun's zenith or of the Earth's magnetic field at a point. On the other hand a line may be curved or crooked and, even if straight, implies no direction. Thus a line of longitude is a great semi-circle joining the two geographic poles on the surface of the Earth and is not a reference of direction.

The difference between 'course' and 'track' is the difference between a 'direction' and a 'line'. A 'course' is a direction and the mariner has always used the term to describe the direction of his path. On the other hand a 'track' is a line which, unless it happens to be a rhumb line, will in fact change direction over the surface of the Earth.

The mariner 'sets' a 'course' and this gives the term a present and a future connotation. From the meaning of the word 'course', a 'course error' must be an error in the direction of travel. The navigator may average a series of past courses and refer to the mean direction as a 'course made good', and he may represent this direction by a straight line on his chart. Nevertheless, a 'course' is a direction and not a line so that the term 'course line' is bad language unless it means a line which represents a course.

Unfortunately, as Alton B. Moody pointed out in his paper 'Do you say what you mean ?', 3 mariners use the term 'course' to mean either the direction through the water or the direction over the bottom. An arbitrary decision may have to be made to decide the issue. Airmen today tend to use the term heading to mean alignment in the air and seamen also use the same term to mean alignment in the water. It follows that there is an argument in favour of confining the term 'course' to mean direction over the bottom and not direction through the water. 
If 'course' can be given this meaning, it will follow that the 'dead reckoning position', which is compounded of 'course' and speed, will mean the geographic position of the craft and not its position as if the sea and the air were stationary. This meaning for 'dead reckoning position' is already accepted in air navigation but is not universally accepted at sea and in particular is not accepted today by the Royal Navy. Perhaps the Institute of Navigation can exercise its powers of persuasion! Otherwise the naval airman may suffer from schitzophrenia!

The term 'track' will cause less difficulty. It is used extensively in air navigation where it refers to the line on the ground or the bottom of the sea over which the craft has passed and has no connection with the line through the air along which the craft has passed. Like a track made in the snow, the word is generally associated with the past. If the navigator has to follow a line in the future he should presumably refer to it as an 'intended track' or as a 'required track'. A 'track error' means an error compared to a line, that is, an error to left or right of the intended track.

It must be faced that, in many instances, the navigator will wish to refer to the direction of his 'track'. He may use the term 'track angle' or 'track angle made good' for the mean direction although he will drop the word angle if it is clearly inferred. Thus track o70T has an unambiguous and clear meaning and can appear quite naturally on track guide systems such as airborne doppler equipments.

It is regrettable that the term 'four course beacon' should have been introduced since it describes a track guide system. Fortunately this bad language will die out as four-course beacons disappear.

Drift and $C_{r a b}$

In everyday language, the word 'drift' suggests a slow steady speed in an unwanted direction. Hence the engineer refers to the drift of a gyro and the mariner to the drift of water. Such a drift can cause an angular deviation to the course of the craft and this angular deviation is naturally known as the 'drift angle'. Obviously the navigator will leave out the word 'angle' where it is clearly inferred and will speak of drift ${ }_{7} R$.

In America the word 'crab' is used instead of 'drift angle'. Crabbing is obviously travelling at an angle like a crab and has no implication of speed. Thus 'crab' is the sideways angle of a craft as viewed from the ground whereas 'drift' is the sideways speed of the ground as seen from the craft. Hence 'crab' is presumably measured from course towards heading, whereas 'drift angle' must be measured from heading towards course.

\section{Height and Altitude}

The word height is used in everyday language to mean the vertical distance above the ground or above some datum. When we say that an aircraft is at a height of $20 \mathrm{ft}$. over a runway or a mountain has a height of $7000 \mathrm{ft}$. above sealevel we know exactly what we mean. However, aircraft generally fly according to barometric altimeter readings and not according to actual height. It is therefore logical for the airman to use the word 'altitude' for the reading of the altimeter and thus to emphasize that the altimeter reading is not a measure of height.

It is unfortunate that the word 'altitude' is easily mistaken in writing for the word 'attitude'. It is also used for height of a heavenly body above the horizon measured in terms of angle. However, this will cause no confusion since the context will make the meaning obvious. 
Summary

Examples have been given of certain words which seem to be used correctly by navigators where there is any chance of ambiguity. It is suggested that, if these and other terms can be formally defined and agreed by the Institutes of Navigation, bad language will gradually die out and confusion in navigation terminology will be reduced to a minimum. A similar exercise might also be undertaken with regard to abbreviations.

It may be that the British Institute of Navigation working with other Englishspeaking Institutes of Navigation could make a start by defining certain words in the hope that they will gradually come to be used with a specific meaning. The alternative is a continuation of the present chaos whereby an official body such as the Airlines Electronics Engineering Committee can decide that 'course' and 'track' have the same meaning ${ }^{4}$ and therefore that a direction is a line.

This note is published with the kind permission of Mr. K. Fearnside, Technical Director of Smiths Aviation Division, but is not intended to represent Company views. Mr. M. W. Richey's advice and help is gratefully acknowledged.

\title{
REFERENCES
}

1 Moody, A. B. Navigation Dictionary. H.O. 220. U.S. Government Printing Office. Washington 25, D.C.

2 Smiths Aviation Division, Navigation Terminology, R.I.D. 624. Smiths Aviation Division, Bishops Cleeve, Gloucestershire, U.K.

3 Moody, A. B. 'Do you say what you mean ?' Navigation U.S.A., 4, 27.

4 Airlines Electronics Engineering Committee. Letter No. 65.1.40. 1700K Street N.W., Washington 6, D.C.

\section{The Exponential Integral Frequency Distribution}

\author{
J. B. Parker
}

I. INTRODUction. In a recent note, D. A. Lloyd 1 has obtained a formula for the frequency distribution of time dependent errors in terms of the exponential integral

$$
-E i(-z)=\int_{z}^{\infty} \frac{e^{-q}}{q} d q
$$

This note clarifies Lloyd's derivations by referring to a theoretically identical, though conceptually different, time-independent, physical model, relates this distribution to one described by Anderson 2 and concludes with a short appreciation of the role of the negative exponential distribution in navigational studies.

2. THE MODEL. We imagine a situation in which the error data are heterogeneous, consisting of a combination of several Gaussian distributions, each of 